\title{
Interpersonal Comparison Versus Persuasive Argumentation: A More Direct Test of Alternative Explanations for Group- Induced Shifts in Individual Choice $^{1}$
}

\author{
Eugene Burnstein," Amiram Vinokur, and YaAcov Trope \\ The University of Michigan
}

\begin{abstract}
One class of theories explains group induced shifts in individual choice in terms of interpersonal comparison process. By comparing himself with others a member finds out that his position is uncomfortably discrepant, e.g., he is overly "cautious" or overly "risky." Knowledge of this discrepancy presunably is necessary and sufficient to induce him to change his initial choice. Another class of theories holds that merely knowing one is different from others is unimportant. Shifts in choice occur because during discussion a member is exposed to persuasive arguments which prior to discussion were not available to him. Thus, if in a factorial design one independently varied (a) the number of others' choices available for comparison and (b) the number of arguments others presented in support of these choices, interpersonal comparison theories would predict the magnitude of the shift to be a function of (a) and not of (b), while theories of persuasive argumentation would predict the opposite. When such an experiment was performed the only reliable main effects were based on the number of arguments, (b), as predicted by persuasive arguments. In no instance did effects involving (a) approach significance.
\end{abstract}

The present study is concerned with certain celebrated revisions of preference following group discussion. Such changes have been labeled "risky" (or "cautious") shifts when group members discussed the choice

${ }^{1}$ This research was supported by a Grant from the National Institute of Mental Health (MH-16950-04) and by a Guggenheim Foundation Fellowship awarded to the first author. Our thinking benefited greatly from the stimulating discussions with colleagues at the University of Provence, particularly those who participated in the seminars of the Social Psychology Laboratory-Robert Abelson, Jean-Paul Codol, Claude Flament, Jean-Pierre Poitou, Marie-France Pichevin, and Christian Rossignol.

${ }^{2}$ Requests for reprints should be sent to Eugene Burnstein, 4136 Institute for Social Research, The University of Michigan, Ann Arbor, MI 48106.

$$
236
$$

Copyright (C) 1973 by Academic Press, Inc.

All rights of reproduction in any form reserved. 
of a probability level, e.g., what is the minimum probability of success one should demand in order to select an uncertain but potentially attractive course of action (see the reviews by Cartwright, 1971; Pruitt, 1971a,b; Vinokur, 1971a). When members discussed some social issue, e.g., was DeGaulle a great leader, the change which resulted was called "polarization" or "extremization" of opinions (Doise, 1969; Gouge \& Fraser, 1972; Moscovici \& Zavelloni, 1969; Myers \& Bishop, 1970, 1971). In attempting to explain these effects some theorists concluded that group discussion was unimportant. The necessary and sufficient condition for producing a shift in choice was that a member recognize his own initial position differed (in a specified direction) from the positions of others. Their explanations, therefore, rely on interpersonal comparisons. Other theorists assumed exposure to or participation in discussion was of critical importance. They stressed persuasive argumentation and, to some extent, differential influence or leadership based on such argumentation. These two classes of theories make quite different predictions, some of which are discussed below.

The importance of persuasive argumentation in group decision making was noted many years ago by Thorndike $(1938 \mathrm{a}, \mathrm{b})$. It has been variously used to analyze group-induced shifts in choice by Nordh $\varnothing \mathrm{y}$ (1962), St. Jean (1970), Stoner (1968), Teger and Pruitt (1967), Vinokur (1971a,b). and Vinokur and Burnstein (1972). The Vinokur version assumes that a particular decision elicits a set of standard arguments in support of the various alternatives among which the person must choose. Presumably the arguments reflect certain cultural values engaged by the decision. A persuasive argument is thought to be similar in effect to that of a correct solution in group problem solving: once made, it is very likely to be accepted either because it is intrinsically cogent, the member who proposes the argument is highly confident of its merits, or both.

The number of arguments available to the average member (or the probability of a particular argument) will viry as a function of the issues raised by the decision. Thus, faced with a particular choice, a very large. a moderate, or an extremely small number of arguments may come to mind. The extent of the shift in choice a group will induce depends on the likelihood that the average member will have available all or most of the persuasive arguments. If the likelihood is very great, then individuals will have already made their initial choice on the basis of all or most of the persuasive arguments. Therefore, not only will they have confidently taken a relatively extreme position beforehand, but they also are unlikely to encounter new persuasive ideas in discussion, ones which had not been considered in making their initial choice. If the likelihood is very small, very few individuals will be able to muster strong support 
for their position during discussion, and thus hardly anyone will have a gond reason for changing their choice. It follows that the largest shifts will be induced by group discussion when persuasive arguments have a moderate likelihood of being available to the average member.

Among the interpersonal comparison theories, Brown (1965), Levinger and Schneider (1969), and Jellison and Riskind (1970) assume that an individual contrasts his choice with the average choice of other members; and they predict, for somewhat different reasons, that relatively moderate choices will be changed so as to be equal to or more extreme than this average. Pruitt (1971a) believes the comparison is made with the most extreme member, to the same effect. The incentive for shifting also varies somewhat from theory to theory. For Brown, the member's choice reflects his adherence to cherished social values; a moderate member will change because he wants to demonstrate at least as much adherence as the others. Jellison and Riskind define the choice (of a "risk" level) as an assertion of ability; because according to social comparison theory, the person wishes to appear slightly more able than others, a shift in choice will be made by the relatively moderate members. Finally, Levinger and Schneider, as well as Pruitt, think the moderate member really wants to take an extreme position but initially suppresses this yearning; the observation that others have made extreme choices legitimizes the desire and allows the member to shift with impunity.

One implication of interpersonal comparison theories is that no shift in choice will occur if members remain ignorant of each other's real preferences; typical shifts will occur, however, when such knowledge becomes available, independent of discussion. Persuasive-argument theory leads one to expect almost the opposite.

Past work on the relative significance of knowledge of other's position and of group discussion had members either discuss without revealing their own choice or reveal their choice without discussing. With the latter paradigm some researchers have observed rather weak shifts (Clark \& Willems, 1969; Teger \& Pruitt, 1967), while most have found no shifts at all (Clark et al., 1971; St. Jean, 1970; Wallach \& Kogan, 1965). The former procedure produced sizable shifts (Clark et al., 1971; St. Jean, 1970). However, reasonably accurate inferences probably could be made about where another member actually stood from what he said in discussion even without his making an explicit statement to that effect.

A recent experiment focusing on these issues obtained results which support the predictions made by persuasive-argument theory and not those made by theories of interpersonal comparison (Burnstein \& Vinokur, in press). For instance, it was found that if a member did not 
know whether others were arguing for their own position or were being forced to support a position contrary to the one they had initially chosen, and the former in fact was the case, typical shifts in choice were obtained: however, if a member had to argue for a position contrary to his own (and thus he would not be able to muster highly persuasive arguments) typical shifts did not occur, even though another's actual choice could be accurately inferred from the position he was required to support in discussion.

There is, however, a more straightforward difference between these two sets of theories which has not yet been examined empirically. In principle, it is a difference which should not be difficult to test by means of a simple factorial design, to wit: one systematically varies the amount of information the subject possesses about others' choices or the positions they have taken independent of the amount of argumentation to which he is exposed in support of these positions. At the very least. interpersonal comparison must predict that considerably more of choice-shift variance will be explained by differences in information about others choices than by differences in amount of persuasive argumentation. Theories based on persuasive argumentation, of course, would predict the opposite. More precisely, in the context of an analysis of variance model, the former theories lead one to expect a main effect based on the amount of information about others' positions or choice, and no main effect for number of arguments; the latter theories demand a main effect for number of arguments and no main effect for number of choices.

This rather simple design, however, poses some technical problems. Although there are a good number of ways to control the amount of information available about others' choices (e.g., see Burnstein \& Vinokur, in press) the problem of controlling the number of arguments to which an individual is exposed is not so readily solved. For example, having subjects discuss their choice for different lengths of time is an obvious method for limiting the amount of argumentation. Yet this would provide only the very crudest control over the actual number of arguments presented during a given interval. Nevertheless, it has been known for some time that merely exposing a subject to a tape recording of group discussion is sufficient to induce a shift in choice (Kogran \& Wallach, 1967; Lamm, 1967). In fact, such findings have been taken as strong evidence for persuasive-arguments theory. Following up this line of research, Vinokur and Burnstein (1972) collected a large number of individual arguments subjects gave to support alternative courses of action in the several decision tasks which are standard in this area. They then presented a small but representative sample of these arguments in 
written form to individuals and found typical, though somewhat attenuated, shifts in choicc. Thus, it sccms feasible to use this pool of arguments for the purposes of the present study. That is to say, by administering different-sized samples of arguments from our pool we can systematically vary the amount of argumentation to which a subject is exposed. Moreover, by associating an explicit choice with one or more of the arguments we can at the same time vary the number of others' choices known to the subject. It should then be possible to determine which, if either, of the two sets of theories is correct-do shifts in choice vary directly with the knowledge a person possesses about others' choices and not with the amount of argumentation presented in support of these choices or vice versa?

\section{METHOD}

\section{Subjects}

A total of two hundred fifty-six male and female students from the introductory courses in psychology at The University of Michigan participated as subjects in this experiment. Participation fulfilled a course requirement. They were run in groups of three to seven subjects. On the average an experimental session lasted for little less than an hour.

\section{Materials and Experimental Conditions}

A set of four Choice Dilemma Questionnaire (CDQ) items were chosen so as to include two "risky" items (i.e., items that have been found to yield reliable "risky" shifts), and two "cautious" items (i.e., items that have been found to yield reliable "cautious" shifts). The two risky items were taken from the original CDQ (numbers 4 and 6 in Kogan and Wallach, 1964, Appendix E). The two cautious items were taken from a questionnaire used by Stoner (1968, numbers 2 and 8 ). These four items were also used by Vinokur $(1971 \mathrm{~b})$ in a set of experiments that replicated the usual findings on these items.

Each choice-dilemma was accompanied by the standard instructions to choosebetween odds of $1,2,3,4,5,6,7,8$ or 9 chances in 10-the lowest odds of success acceptable in order to recommend trying the uncertain (i.e., risky) alternative; or, instead, to indicate that this alternative should not be attempted, no matter what the odds. In the latter case, a response is usually scored as 10 . A choice is measured as the odds that are chosen by the subject. The four items were preceded by the standard instructions and assembled in a questiomnaire entitled "Opinion Questionnaire."

In addition to the Opinion Questionnaire, each subject was given a booklet which contained choices (in terms of $1,2, \ldots$, or 10 chances in 10 ) made by other subjects as well as the best arguments they produced in support of their positions. Each booklet contained four sets of materials relevant to the four items described above. Depending on the experimental condition, each set consisted of either one or five positions taken by others and five or twenty-five arguments. The number of positions for the two levels of the first factor (one and five positions) were chosen to correspond to the minimum number of positions possible (one) and to the most common number of positions or group size for this area of research (five). Correspondingly, 
the number of arguments for the two levels of the second factor were chosen to include a minimum of one argument per position for the lowest level (a minimum of five argmments to match five positions) and the average number of arguments produced by a group of five subjects (twenty-five arguments). The latter value was determined in an earlier analysis of arguments generated in response to CDQ items (Vinokur \& Burnstein, 1972).

The arguments belonging to a particular position were placed next to it. Thus, four sets of booklets were used in this experiment. Each set defined an experimental condition as follows: Condition I contained one position accompanicd by five arguments: Condition II, one position accompanied by twenty-five arguments; Condition III, five positions, each accompanied by one argument: and Condition IV, five positions, each accompanied by five arguments.

The positions and the arguments were matched in a particular way. The positions appearing in each set were a random sample of the initial positions of subjects obtained from the data of Vinokur's (1971b) experiment. The arguments were randomly selected from the large pool of pro-risk and pro-caution arguments collected by Vinokur and Burnstein (1972). The main constraint was that arguments selected to go along with a specific position had, on the whole, to be consistent with the latter. Thus, in booklets used in Conditions I, II, and IV, each risky position (above the mean "riskiness" for that item) was accompanied by a majority of pro-risk argiments and a minority of pro-caution items. The size of the majority increased with the extremity of the position. For example, in Condition I (one position and five arguments) for item 4, a "risky" CDQ item used in the present study, a position of 1 in 10 would be accompanied by 5 or 4 pro-risk arguments; a position of 4 in 10 would be accompanied by 3 pro-risk arguments and 2 pro-caution arguments. The opposite was true for cautious choices, a position of 9 in 10,8 in 10 , etc. In the booklets used in Condition III each position was accompanied by one argument. I "risky" position was assigned a pro-risk argument and a "cantious" position was assigned a pro-caution argument.

\section{Procedure}

Sulbjects irriving at the laboratory were seated at small tables. Each received a questionnaire containing the standard instructions for responding to choice-dilemma items, a practice item, and the four items described above. After the questionnaires vere completed they were collected. Then, depending on the experimental situation, subjects received the booklets with arguments and positions described above and a new copy of the Opinion Questionnaire with the four items. They were then asked to read the instructions attached to the booklet. These instructions were identical for all the four conditions. The last part of these instructions, which serve as a final :ammary, read as follows:

"Again, the arguments and the choices they acconpany were made by subjects like yourself and reflect their opinions concerning the choice dilemma situations. Some of these arguments and choices may be valid and sound whereas others may not. It partly depends on the lind of assumptions and inferences that you consider reasonable in light of the information available in the choico-dilemma situation. Furthermore, you may find that some arguments raise new points or illuminate new aspects of the problem that you have not thought about before and have not taken into consideration. It is entirely up to you to determine the soundness and nsefulness of the

"The complete set of instructions can be obtained from the authors. 
arguments and the choices they accompany and, accordingly, how to utilize them. What we want is that you carefully examine the arguments and the choices so that you make the best possible decision on the probability scale.

Please do not feel bound by what you marked before. What is important is that you consider the problems, the arguments, and the choices carefully and seriously and check what you consider the best decision now."

After subjects completed their work on the second questionnaire, the nature and purpose of the experiment was explained at length.

\section{RESULTS AND DISCUSSION}

An analysis of variance was performed on shift scores, that is, on the difference between a subject's choice before and after he learned what position others have taken and what arguments they made to support their position. The direction of the shift for a particular CDQ type item is remarkably reliable. Since the magnitude of the shift in choice was at issue and not the direction, shift scores for all four items were combined, irrespective of their direction. A summary of the analysis is shown in Table 1. The only reliable main effect is based on number of arguments. The items were then broken into those which shift toward "risk" and those which shift toward "caution." Separate analyses of each set reveal main effects for number of arguments. In no instance do effects based on the number of others' choices (positions) approach acceptable levels of statistical significance. A summary of these analyses is given in Table 2. Mean shifts in choice are presented in Table 3. On the whole the results strongly support persuasive argument theories. Along with the findings from our earlier study (Burnstein and Vinokur, in press), they imply

TABLE 1

Summary of the Analysis of Variance of Shifts in Individual Chotce Following Exposure to the Arguments and Positions of Others

\begin{tabular}{lrcc}
\hline Source & $d f$ & MS & F \\
\hline Between subjects: & 1 & 10.27 & $6.69^{*}$ \\
Arguments (A) & 1 & 3.87 & 2.52 \\
Positions (P) & 1 & 0.90 & $<1$ \\
A $\times$ P & 252 & 1.53 & \\
Error & & & $<1$ \\
Within subjects: & 1 & 1.17 & $<1$ \\
Item type (I) & 1 & 0.004 & 1.77 \\
A $\times$ I & 1 & 0.67 & \\
P $\times$ I & 1 & 2.60 & 1.46 \\
A $\times$ P $\times$ I & 252 & & \\
Error & & & \\
\hline
\end{tabular}

${ }^{*} p<0.05$. 
TABLE 2

Summary of the Analyses of Varianch of Shifts in Chotce for "RIsky" Items and FOR "C.luthous" Ithims

\begin{tabular}{|c|c|c|c|c|c|c|}
\hline \multirow{2}{*}{$\begin{array}{c}\text { Item type } \\
\text { Source }\end{array}$} & \multicolumn{3}{|c|}{ Risky items $(A \& B)$} & \multicolumn{3}{|c|}{ Cautions items $\left(F_{+} \& \mathrm{P}\right)$} \\
\hline & lf & Ms & $\mathrm{F}$ & $d i$ & Ms & $\mathrm{F}$ \\
\hline$\ldots$ & - . & - - - - - - & $-\ldots-$ & 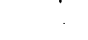 & & \\
\hline Arguments (A) & 1 & 4.92 & $3.55^{*}$ & 1 & 5.35 & $: 2.23^{*}$ \\
\hline Pusitions $(\mathrm{P})$ & I & 3.87 & 2.82 & 1 & 0.660 & $<1$ \\
\hline $\mathrm{A} \times \mathrm{P}$ & 1 & 0.22 & $<1$ & i & $3.2 \mathrm{x}$ & $2(1)$ \\
\hline Eiror & 252 & 1.37 & 252 & 252 & 1.62 & \\
\hline
\end{tabular}

${ }^{*} p<0,0 \AA$.

that at best intcrpersonal comparison processes are relatively umimportant for understanding the choice-shift phenomenon. ${ }^{4}$

Nevertheless, interpersonal comparison processes still cannot be dismissed as completely irrelevant. An examination of the mean shifts in Table 3 indicates a comparatively modest yet noticeable shift in choice when argumentation is minimal but several others' choices are known

TABLE: 3

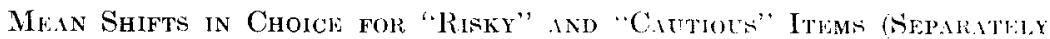
and Combined) as a Function of Nrmbliz of Argimantis anj Numbir of Positioniti

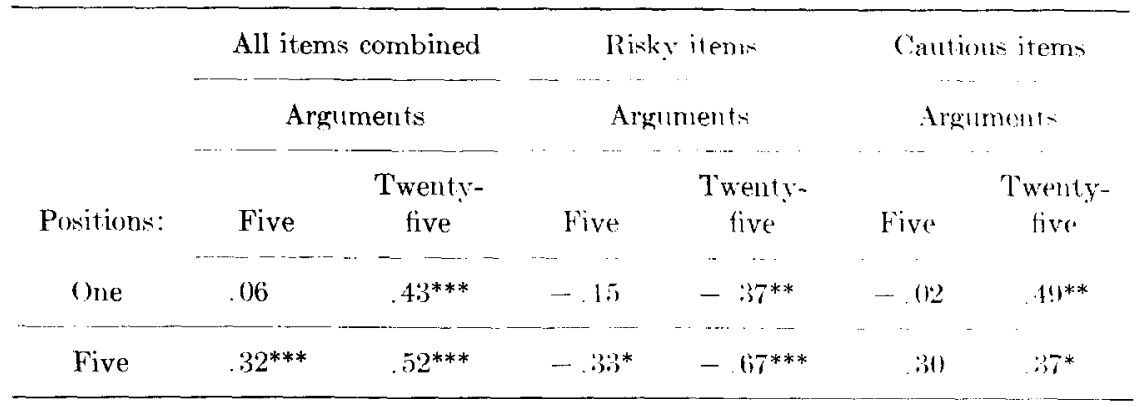

${ }^{a}$ For the risky and cautious items negalive values dewignate "lisky" shifts and powitive values designate "cautious" shifts. For all items combined the valnes indirate. the overall magnitude of the shift of the direction.

${ }^{*} p<0.05$.

${ }^{* *} p<0.01$.

${ }^{* * *} p<0.001$.

The magnitudes of the shifts produced by 25 arguments are similar to those obtained in Vinokur and Burnstein (1972) where an identical number of arguments were selected at random from a larger pool. This suggests that in spite of the cunstraints placed on the selection of arguments in the present study, they probably were not unrepresentative. 
(the five arguments-five positions cells). At present one can only conjecture about the persistence of weak interpersonal comparison effects, and because these effects were so weak we do not intend to conjecture at length: It may well be the case that when a person reconsiders an initial choicc his first prefercnce is to do this in the light of information contained in the arguments-if for no other reason than these statements provide better or more information for evaluating alternatives than the mere choices of others. However, when only the latter are available, they will be put to use. But perhaps not as interpersonal comparison theorists imagine. Thus, knowledge that others' choices are discrepant from his own may induce the person to reconstruct a line of reasoning which he thinks could have produced such choices. That is to say, knowing others have chosen differently stimulates the person to generate arguments which could explain (and thus would support) their choices. Therefore, according to our conjecture, informing the person that others took a position more extreme than his own does not serve so much to threaten his self-esteem or to legitimize some suppressed yearning but rather induces him to find a reasonable explanation for the difference.

\section{REFERENCES}

Brown, R. Social psychology. New York: Free Press of Glencoe, 1965.

Bunnstein, E., \& Vinokuk, A. Testing two classes of theories about group-induced shifts in individual choice. Joumal of Experimental Social Psychology, in press.

CARTwRight, D. Risk taking by individuals and groups: an assessment of research employing choice dilemma. Journal of Personality and Social Psychology, 1971, 20, 361-378.

Clark, R. D., Crockett, W. H., \& Archer, R. L. Risk as value hypothesis: the relationship between perception of self, others, and the risky shift. Journal of Personality and Social Psychology, 1971, 20, 425-429.

Clark, R. D., \& WILlems, E. P. Where is the risky shift? Journal of Personality and Social Psychology, 1969, 13, 215-221.

Dorse, W. Intergroup relations and polarization of individual and collective judgments. Journal of Personality and Social Psychology, 1969, 12, 136-143.

Gouge, C., \& Fraser, C. A further demonstration of group polarization. European Journal of Social Psychology, 1972, 2-1, 95-07.

JeLcrson, J. M., \& Riskind, J. A social comparison of abilities interpretation of risk taking behavior. Journal of Personality and Social Psychology, 1970, 15, 375-390.

Kogan, N., \& Wallach, M. A. Risk taking: a study in cognition and personality. New York: Holt, Rinehart and Winston, 1964.

LAMM, H. Will an observer advise higher risk-taking after hearing a discussion of the decision problem? Journal of Personality and Social Psychology, 1967, 6, $467-471$.

Levinger, G., \& Schnemer, D. J. A test of the risk is a value hypothesis. Journal of Personality and Social Psychology, 1969, 11, 165-169.

Moscovici, S., \& Zavalloni, M. The group as a polarizer of attitudes. Journal of Personality and Social Psychology, 1969, 12, 125-135. 
Mrers, D. G., \& Brshop, G. D. Discussion effects on racial attitudes. Science, 197(). $169,778-779$.

Myers, D. G., \& Bishop, G. D. Enhancement of dominant attitudes in group discussion. Journal of Personality and Social Psychology, 1971, 20, 386-391.

NoнDнфy, F. Group interaction in decision-making under risk. Unpublished master's thesis, School of Industrial Management, Massachusetts Institute of Tochnology, 1962.

Prurt T, D. G. Choice shifts in group discussion: an introductory review. Jommol of Personality and Social Psychology, 1971, 20, 339-360, a.

Prust , D. G. Conchusions: toward an understanding of choice shifts in group discussion. Journal of Personality and Social Psychology, 1971, 20, 495-510, b.

St. Jean, R. Reformulation of the value hypothesis in group risk taking. Proceedings of the 78th Annual Convention of the American Psychological Association. 1970. 5, 339-340.

Stoner, J. A. F. Risky and cautious shifts in group decisions. The influence of widely held values. Journal of Experimental Social Psychology, 1968, 4, 442-4.5.9.

Teger, A. I., \& Pruitr, D. G. Components of group risk taking. Journal of Experimental Social Psychology, 1967, 3, 189-205.

Thorxdike, R. L. The effect of discussion upon the correctness of group decisions, when the factor of majority is allowed for. Joumal of Social Psycholozty. 19838. 9, 343-362, a.

Tнонndike, R. L. On what type of task will a group do well? Joumal of Aburmal and Social Psychology, 1938, 33, 409-413, b.

VINokur, A. Review and theoretical analysis of the effects of group processes upm individual and group decisions involving risk. Psychological Bulletin, 1971. 76. 231-250, a.

VinоктR, A. Cognitive and affective processes influencing risk-taking in groups: an expected utility approach. Journal of Personal and Social Psychology, 1971. 20, $472-486, b$.

VivokuR, A., \& Bunstein, E. The effects of partially shared persuasive argments on group induced shifts: a group problem-solving isproach. Unpublished mamuscript, The University of Michigan, Research Center for Croup Dynanics, 1972

WaLlaCH, M. A., \& Kogan, N. The roles of information, discussion, and consensits in group risk taking. Journal of Fxperimental Social Psycholopy, 1965, 1, 1-19.

(Received November 1, 1972) 